\section{Conclusion}

To bring libraries up to the standard necessary to support the needs of those working in hospitals requires a constant and sustained effort. The development of Regional Library systems has already shown the marked difference between those libraries within such a system and the fragmentation and waste of resources in those Regions that do not have Regional coverage. This work should not be one-sided, though, and all librarians, whether local or Regional, have the case for these essential improvements greatly strengthened if the demand comes equally from the users. If a librarian is trying to persuade the Administrators of the need for additional resources, the stock reply is often that there have been no complaints or demands. It is in the interests of all users to press for better facilities, and psychiatrists are more fortunate than most in that the College's Approval Teams are laying more and more emphasis on adequate library facilities being an important criterion for recognition.

Active co-operation is at present taking place between the Regional Librarians Group and the Royal College of Psychiatrists to try to devise a standard method of assessing the adequacy or otherwise of a library.

It is realized that overnight transformation is impossible, but if all those who need and use library and information services keep up steady and unrelenting pressure, progress can be made.

\title{
The Policy of the College Library
}

\section{HenRy R. Roluin, Honorary Librarian, Royal College of Psychiatrists}

The role of the College library has hitherto not been defined. This is perhaps to be explained by the fact that, prior to our translation to 17 Belgrave Square, there has never been a library in the sense of a room or rooms exclusively given over to its use. An equal, if not more serious handicap, was the lack of the services of a professional librarian. Now these difficulties have been overcome. We have an elegant, well-appointed room in which to do our job and the work of our newly-appointed librarian, Mrs Susan Floate, cannot be too highly praised.

For the first time, therefore, we are in a position to frame a policy and it is as well to this end to be realistic and to appreciate what we cannot do. Thus:

(i) We cannot provide total library facilities in the way that the RSM does.

(ii) We cannot offer a comprhensive journal service, and with the services of the British Library Lending Division so readily available, it would be foolish to even try.

What we can do, however, is:

(i) To make what books, journals and memorabilia that we have readily available to the membership and to other bona fide scholars. With this in view, the library has been so designed and furnished as to provide comfortable chairs and tables at which to work.

(ii) Within certain limits, to loan books to members; but the prohibitive cost now makes a postal service impossible. For very obvious reasons our valuable antiquarian books cannot be loaned.

(iii) To answer enquiries by telephone-it should be noted that in this respect business is already brisk.

(iv) To collect and catalogue the memoranda and other documents issued by the College.

(v) To continue to collect books on psychiatry-modern, antiquarian and covering the history of the specialty. It is imperative at this point to express our thanks to members who have so generously donated copies of their works to the Library.

(vi) To expand the classification, cataloguing and indexing of the collection.

But when all is said and done, the Library is there to serve the membership and we would welcome suggestions that would make us more efficient. A library is a vital artery in the body-politic of a College such as ours. It is for the members to keep their fingers on the pulse of that artery, and should they note any irregularities in its rate or volume, to take steps to ensure a speedy return to healthy action. 